\title{
NASKAH BABAD NITIK SULTAN AGUNG : SEBUAH PRODUK KEBUDAYAAAN JAWA
}

\section{NASKAH BABAD NITIK SULTAN AGUNG : A JAVANESE CULTURAL WORK}

\author{
Kamidjan \\ Jurusan Pendidikan Bahasa dan Sastra Indonesia, Fakultas Bahasa dan Seni, \\ Universitas Negeri Surabaya. Jalan Lidah Wetan, Surabaya \\ Tanggal naskah masuk: 27 September 2012 \\ Tanggal revisi terakhir: 20 November 2012
}

\begin{abstract}
As a Social and cultural document, manuscript of babad Nitik Sultan Sagung is one of Javanese literature works consisting of some cultural values which are related to local wisdom. Such cultural values refers to what Jamaris quotes as human interaction to God, human interaction to nature, and human interaction to society. Each value is in relation to another. As a social creature, human depend upon other persons.
\end{abstract}

Keyword: a javanese cultural work

\begin{abstract}
Abstrak
Sebagai dokumen sosiobudaya, Babad Nitik Sultan Agung merupakan salah satu karya sastra Jawa yang mengandung nilai-nilai budaya yang berkaitan dengan kearifan lokal. Nilai-nilai budaya tersebut mengacu pada pendapat Jamaris, meliputi hubungan manusia dengan Tuhan, dengan alam, dengan masyarakat, dengan sesama dan dengan dirinya. Nilai-nilai tersebut tidak bisa dilepaskan antara satu dengan yang lain. Sebagai makhluk sosial, manusia tidak bisa hidup tanpa bantuan orang lain.
\end{abstract}

Kata Kunci: produk kebudayaan Jawa

\section{Pendahuluan}

Sastra merupakan bagian dari kebudayaan dalam arti luas. Sastra bukan hanya milik masyarakat, yang diturunkan dari generasi ke generasi. Sastra mencurahkan ide seorang pengarang, yang mewakili masyarakat, dapat berperan aktif dalam jangka waktu yang cukup panjang. Sastra memiliki fungsi dalam alam pikiran dan mampu membentuk norma dalam masyarakat pada zamannya dan masa mendatang (Robson, 1978:7) ${ }^{1}$. Sastra mampu membantu manusia dalam menghadapi masalah yang timbul dalam kehidupan sehari-hari. Hal itu bergantung dari tujuan pengarang dalam menciptakan karya sastra. Mereka bukan menyediakan bahan pelajaran, mencari uang atau kepuasan 
pribadi. Sastra klasik menyediakan bahan yang perlu dikaji guna kepentingan masyarakat di masa kini dan masa yang akan datang. Sebagai bagian dari kebudayaan, karya sastra berhubungan erat dengan filsafat dan berbagai bentuk kesenian. Oleh sebab itu, karya sastra dapat dianalisis dengan barmacam-macam pendekatan untuk mengungkapkan jerih payah para pengarang yang dituangkan dalam karyanya.

Sastra merupakan bagian dari kebudayaan, yang lebih menekankan pada unsur keindahan. Sastra memberi manfaat melalui isi, seperti pesan, dan nasihat yang diperoleh melalui aspek etika (Ratna, 2002:415) ${ }^{2}$. Selanjutnya, dikatakan bahwa sastra dengan medium bahasa metaforis konotatifnya berfungsi untuk menampilkan kembali berbagai peristiwa kehidupan manusia agar dapat mengidentifikasikan dirinya dalam rangka menciptakan medium yang tersedia.

Karya sastra diciptakan sebagai wahana untuk mengungkapkan pikiran, gagasan perasaan dan perasaan masyarakat. Dengan membaca karya sastra klasik, masyarakat bisa berkomunikasi dengan masyarakat abad lalu. Masyarakat berbicara melalui apa yang ditulis, tetapi kita juga tidak harus menirunya sebab masyarakat bersifat dinamis. Yang masih bisa, dimanfaatkan sedang yang usang dan merugikan, sebaiknya ditinggalkan. Masyarakat juga harus maju agar tidak ketinggalan zaman.
Modernisasi tidak bisa dihindari. Akan tetapi bagi bangsa Indonesia yang dianggap maju adalah kebudayaan yang kebarat-baratan, dan sebaliknya kebudayaan Indonesia dianggap kuna dan terbelakang (Robson, 1994:8) ${ }^{3}$. Bila bangsa lain seperti Cina, India, Arab, dan Jepang melestarikan huruf dan menghargai sastra klasiknya, maka bangsa Indonesia justru dianggap rendah diri budaya. Kita dianggap ragu dan lemah untuk melestarikan, mempelajari, dan menegaskan nilai karya sastra. Sikap tersebut menyulitkan untuk menunjukkan bahwa karya klasik dapat digunakan zaman kini dan mendatang dalam usaha membentuk kebudayaan nasional, yang terdiri atas puncakpuncak kebudayaan daerah yang dapat dipakai sebagai identitas Indonesia atau kebanggaan prestasi masa lalu. Oleh sebab itu, nilai-nilai budaya Jawa yang terpendam dalam karya sastra perlu digali.

Menggali dan mengungkapkan nilai-nilai budaya yang terkandung dalam sastra klasik sebaiknya dilandaskan pada zaman karya sastra itu digubah dengan jalan menafsirkan pada setiap nilai. Nilai-nilai itu diaktualisasikan dengan situasi sekarang dengan pemahaman dan pendalaman sehingga dapat disarikan nilai-nilai yang relevan, dan adanya keterkaitan antara nilai budaya lama dengan budaya sekarang. Nilai-nilai itu mengandung fungsi tertentu bagi pemenuhan kebutuhan hidup 
masyarakat pada zamannya (Purnomo, 2007:13) $)^{4}$.

Naskah Babad Nitik Sultan Agung merupakan hasil cipta sastra Jawa klasik yang sarat dengan nilai budaya. Pengungkapan nilai-nilai budaya dalam naskah sebagian besar bersifat simbolis. Oleh sebab itu, kajian ini bersifat interpretatif, tepatnya menggunakan pendekatan hermeneutik.

Babad Nitik Sultan Agung berisi kisah sejarah bercampur dongeng tentang kerajaan Mataram di bawah pemerintahan Panembahan Seda Krapyak dan Sultan Agung. Kisah ini diawali dengan keterangan tentang keluarga Panembahan kemudian ajarannya kepada Adipati Anom; perkawinan dengan Retno Suwidi (Kanjeng Ratu Kidul) dan penobatan sebagai raja Laut Kidul. Sultan Agung kemudian menaklukkan dengan damai negara Palembang, Minangkabau, Aceh, Selan, dan Banjar. Kemudian mengadakan perjalanan ke Mekah; pada waktu yang sama Panembahan Krapyak wafat, sementara diganti Pengeran Martapura, akhirnya diganti Sultan Agung. Kemudian perjalanan ke Banten, lalu membangun kota Karta. Perjalanan ke Ngerum, Mekah, Persi, Makasar, Siyem. Pembangunan makam Imogoro. Persaingan kebolehan Sultan Agung dengan Kyai Penghulu Amat Kategan berakhir dengan keadaan di negara Karta (Behrend, 1990).

Naskah ini terdapat di beberapa perpustakaan dan Museum, seperti: Perpustakaan Leiden (Belanda),
Museum dan Perpustakaan Kraton Yogyakarta, dan Museum Sonobudoyo Yogyakarta. Semua naskah sama isinya yang berbeda manggala dan kolofonnya. Behrend (1990: 32) menyatakan bahwa naskah ini ditulis oleh Pengeran Harya Candranagara II di Yogyakarta.

Tulisan ini berusaha mengungkapkan unsur budaya Jawa yang tertuang dalam Naskah Babad Nitik Sultan Agung. Nilai-nilai budaya itu diharapkan dapat dipakai sebagai media pendidikan moral bagi generasi muda, sesuai yang dikemukakan oleh ${ }^{5}$ Robson (1978). Karena sastra klasik memiliki nilai yang tinggi walau nilai itu kadang kurang jelas. Unsur nilai budaya merupakan hasil interpretasi penulis berdasarkan pemikiran dan pemahamannya.

Definisi yang dikemukakan Koentajaraningrat itu terdiri atas dua macam, pertama definisi yang cakupannya lebih sempit. Kebudayaan diartikan sebagai kesenian. Kedua, definisi kebudayaan cakupannya lebih luas karena tidak hanya mencakup kesenian, tetapi juga aspek yang lain, seperti pikiran, karya manusia, dan hasil kerja manusia yang berupa bendabenda, termasuk di dalamnya karya sastra, seperti naskah.

Karya sastra dipandang sebagai dokumen sosiobudaya yang mencatat kenyataan sosiobudaya suatu masyarakat pada masa tertentu. Pendekatan ini hanya tertarik kepada unsur-unsur sosiobudaya dilihat 
sebagai unsur-unsur yang lepas (Yunus, 1986:3) ${ }^{6}$. Setiap unsur dalam karya sastra dianggap mewakili secara langsung unsur nilai-nilai budaya. Nilai budaya dalam karya sastra merupakan pengungkapan tata nilai yang tumbuh dan berkembang dalam masyarakat berfungsi untuk mencari keseimbangan dalam tatanan kehidupan.

Tata nilai terdapat dalam berbagai aspek budaya. Salah satu aspek budaya yang sampai sekarang masih dilestarikan oleh masyarakat adalah tradisi. Salah satu tradisi itu adalah pemujaan terhadap arwah nenek moyang. Hal ini menunjukkan bahwa sikap mikul dhuwur mendhem jero tetap dijunjung tinggi oleh masyarakat. Mereka menganggap bahwa setiap manusia berusaha memenuhi aturanaturan dan tata nilai untuk menjaga keseimbangan dunia. Tata aturan maupun tata nilai biasanya direalisasikan dalam bentuk tradisi yang disepakati oleh anggotanya. Nilainilai itu secara tidak sengaja akan terbentuk dalam masyarakat dan dijadikan anutan dari generasi ke generasi, sangat berarti dan bernilai. Nilai-nilai itu akhirnya menjadi konsep yang hidup di alam pikiran masyarakat.

Dalam usaha melestarikan nilainilai budaya bangsa, sastra tradisional memiliki peran dan fungsi yang perlu dipertimbangkan karena masyarakat yang mempunyai perhatian pada kesusasteraan dan wawasan tentang sastra tradisional semakin berkurang (Ikram, 1997:157) ${ }^{7}$. Dengan demikian peluang yang dimiliki oleh masyarakat tentang informasi yang tertuang di dalamnya semakin sempit. Setelah mereka merasa kehilangan mulai memikirkan bagaimana memperolehnya kembali. Tetapi keinginan mereka terbentur oleh asumsi apakah nilai-nilai tersebut masih bisa difungsikan. Walaupun nilai-nilai budaya sejak zaman dulu hingga kini tidak pernah terputus, melainkan berkesinambungan.

Koentjaraningrat, $\quad(1982: 193)^{8}$, mendokumentasikan nilai-nilai budaya Jawa yang mengacu kepada pendapat Kluckhohn yang sejalan dengan pandangan hidup orang Jawa. Nilainilai budaya tersebut dibedakan menjadi (1) hakikat hidup manusia, (2) karya manusia dan etos kerja, (3) hubungan manusia dengan alam, (4) hubungan manusia secara horisontal dan (5) maupun vertikal. Nilai-nilai budaya adalah lapisan paling abstrak dan luas. Tingkat ini merupakan ide-ide yang mengonsepsikan hal-hal yang paling bernilai dalam kehidupan masyarakat.

Nilai-nilai budaya berfungsi sebagai tata aturan dalam tingkah laku manusia, yang lebih konkrit, seperti norma, hukum, dsb. yang berpedoman kepada sistem nilai budaya. Sistem tersebut dibedakan menjadi 5 kategori berdasarkan (1) hubungan manusia dengan Tuhan (2) hubungan manusia dengan alam, (3) hubungan manusia 
dengan masyarakat (4) hubungan manusia dengan sesama dan (5) manusia dengan diri sendiri (Djamaris, 1996: 4) ${ }^{9}$. Konsep tersebut digunakan untuk mengkaji nilai-nilai budaya dalam naskah Babad Nitik Sultan Agung.

\section{Naskah dan Budaya Jawa}

Kebudayaan adalah ide-ide dan pemikiran manusia, karya, dan hasil karya manusia yang berdasarkan pikiran dan akal budinya. Manusia melakukan suatu proses setelah melakukan pemikiran atau proses belajar. Konteks kebudayaan itu dalam pengertian yang luas. Artinya, tidak hanya kebudayaan Jawa, tetapi kebudayaan untuk seluruh bangsa. Kebudayaan Jawa memiliki ciri tersendiri, demikian juga kebudayaan suku bangsa yang lain, seperti kebudayaan Bali, kebudayaan Lombok, Sumbawa, dan sebagainya.

Ide-ide, pandangan hidup dan pemikiran manusia banyak terdapat dalam sastra Jawa khususnya sastra Jawa klasik. Sebagai dokumen sosio budaya sastra memuat berbagai aspek kehidupan manusia. Termasuk di dalamnya nilai-nilai budaya dan berbagai catatan peristiwa pada zamannya. $\quad{ }^{10}$ Pigeaud (1967:2) membagi karya sastra Jawa menurut isi menjadi 4 kalompok meliputi (1) agama dan kesusilaan), sejarah dan mitologi, susastra dan bunga rampai. Kelompok kedua, sejarah dan mitologi, memuat berbagai catatan peristiwa dan nilai budaya masyarakat.

Babad merupakan genre sastra sejarah, di Jawa, Sunda, Madura Bali dan Lombok (Darusuprapta,1975) ${ }^{11}$. Selain mencatat berbagai peristiwa penting babad berisi cerita-cerita mite mengenai penciptaan dunia dengan unsur-unsur Hindu dan Budha yang dominan tentang kerajaan di Jawa, yang sifat setengah historis. Di dalamnya terdapat unsur-unsur Islam seperti para wali, nabi, malaikat. Di samping itu juga ditampilkan tokohtokoh Hindu-Budha, seperti para dewa, dan tokoh-tokoh Pandawa. (Koentjaraningrat, 1984:330-331) ${ }^{12}$. Buku babad sangat dihargai oleh pusatpusat kebudayaan, kerajaan Mataram khususnya Kasultanan Yogyakarta dan Kasunanan Surakarta Hadiningrat. Babad merupakan salah satu karya sastra yang sangat diagungkan.

\section{Naskah Babad Nitik Sultan Agung}

Babad Nitik Sultan Agung merupakan salah satu karya sastra produk istana kraton Yogyakarta. Naskah ini diproduksi oleh Pujangga Kasultanan Ngayojakarta Hadiningrat, sekitar abad ke-19. Sultan Agung merupakan salah satu tokoh yang menurunkan para raja di Yogyakarta dan Surakarta.

Salah satu Naskah Babad Nitik Sultan Agung koleksi Museum Sonobudoyo Yogyakarta, bernomor SB. No. 30 akan dikaji difokuskan pada nilai-nilai budaya. Dalam kolophon 
dijelaskan bahwa naskah tersebut, penyalinan dimulai pada tanggal 24 Jumadilawal, tahun Jimakir 1802 (Dwi ngambara ngesti tunggal) bertepatan dengan tanggal 9 Juli 1873. Selesai ditulis 23 Jumadilakir tahun Ehe 1806 atau 16 Juli 1876. Nakah disalin oleh Dyan Riyo Danuatmaja atas perintah Jeng Rahadyan Mertanagara.

Bentuk naskah ini berbentuk tembang macapat. Pupuh yang terdapat dalam manuskrip Babad Nitik Sultan Agung sebagai berikut: Berdasarkan paparan pada tabel tersebut dapat disimpulkan bahwa naskah tersebut terdiri atas 36 pupuh tembang macapat, yaitu (1) Dhandhanggula (lima pupuh), (2) Asmaradana (tujuh pupuh), (3) Mijil (empat pupuh), (4) Kinanthi (dua pupuh), (5) Durma (dua pupuh), (6) Gambuh (satu pupuh), (7) Sinom (tujuh pupuh), (8) Pangkur (empat pupuh), (9) Megatruh (dua pupuh), (10) Girisa (satu pupuh), dan (11) Maskumambang (satu pupuh).

\subsection{Isi Ringkas Naskah}

Naskah Babad Nitik Sultan Agung versi di atas ini menceritakan sejarah bercampur mitos, diawali Sultan Agung semasa menjadi Adipati Anom kerajaan Mataram meninggalkan istana, merantau ke seluruh pelosok Mataram. Beliau mengembara ke negara di luar Mataram, seperti Malaka, Singapura, Siam (Thailand), Kamboja, Arab dan Ngerum. Di samping itu, beliau juga menjelajah ke alam gaib, terutama keraton Nyai Rara
Kidaul di Laut Selatan. Setelah menjadi Sultan di Mataram mulai menaklukkan Surabaya, Palembang, Banten, Cirebon, Makasar, Riau, dan Bali. Beliau juga berkelana ke Rum. Sekembali dari Rum membangun makam Imogiri. Semula beliau akan membangun makam di Mekah, namun dilarang oleh penguasa negara Mekah, dengan bantuan para ulama ia membangun makam Imogiri, yaitu terletak di sebelah selatan kerajaan Mataram. Sultan Agung juga senang terhadap kesenian dan kebudayaan. Dalam naskah dikisahkan, beliau sering menonton wayang golek Sunda. Di samping itu, mendapat tugas mengembangkan agama Islam di Jawa.

\subsection{Nilai Budaya dalam Babad}

\section{Nitik Sultan Agung}

Unsur budaya yang dikaji dalam naskah Babad Nitik Sultan Agung adalah budaya yang berkaitan dengan nilai-nilai yang bersifat spiritual karena unsur nilai budaya ini yang dominan pada naskah tersebut. Untuk menganalisis nilai-nilai budaya yang tertuang dalam Naskah Babad Nitik Sultan Agung digunakan teori yang dikemukakan oleh Djamaris, meliputi hubungan manusia dengan Tuha, dengan alam, masyarakat, sesama dan dirinya. Kajiannya sebagai berikut:

\section{(1) Hubungan Manusia dengan}

\section{Tuhan}

Kepercayaan manusia terhadap keberadaan Tuhan tertanam sejak 
mereka diciptakan. Hal itu tampak bahwa sejak zaman prasejarah masyarakat Jawa telah mengenal adanya Tuhan. Mereka mencari keberadaan-Nya lewat animisme dan dinamisme. Masuknya agama Hindu dan Budha menambah kepercayaan mereka karena tidak bertentangan dengan pandangannya. Demikian juga dengan masuknya pengaruh Islam. Hingga kini berbagai macam kepercayaan dan pandangan keagamaan masyarakat bersifat dinamis, berkembang sejalan dengan perkembangan zaman. Bahkan di antara kepercayaan itu terjadi sinkritisme. Sinkritisme itu tampak dalam kehidupan sehari-hari yang hingga kini masih dilaksanakan. Salah satu di antaranya adalah pemujaan terhadap arwah nenek moyang dan adanya makhluk halus di sekitar kehidupan mereka. Manusia berusaha menyelaraskan diri dengan alam sekitarnya untuk menjaga keseimbangan dunia.

Dalam Babad Nitik Sultan Agung, hubungan manusia dengan Tuhan mengarah kepada ajaran Islam. Oleh sebab itu, analisis nilai budaya dalam hubungan manusia dengan Tuhan, diarahkan pada kepercayaan masyarakat yang berkaitan dengan agama Islam, di antaranya:

\section{(a) Percaya Adanya Tuhan}

Percaya adanya Tuhan bagi umat manusia tumbuh di lubuk hati, tak kuasa diingkari dan bersifat manusiawi.
Mereka percaya bahwa Ia ada dan Maha Esa Maha segalanya. Umat manusia mencari keberadaan-Nya dan berusaha dekat dengan-Nya.

Sejak zaman prasejarah masyarakat Jawa mencari lewat animisme dan dinamisme. Kedatangan umat Hindu dan Budha dari India dan Islam dari Arab ke Indonesia mempertebal keimanannya. Bahkan dalam kehidupan sehari-hari terjadi sinkritisme antara kepercayaan Jawa asli, Hindu dan Islam berbaur menjadi satu walau sebagian besar masyarakat Jawa memeluk agama Islam, tetapi dalam kehidupan bermasyarakat pembauran kepercayaan itu tetap berjalan, yang direalisasikan dalam bentuk berbagai macam tradisi yang hingga kini masih tetap dilestarikan. Pembauran atau sikritisme kepercayaan itu juga tempak dalam berbagai karya sastra terutama sastra klasik.

Naskah Babad Nitik Sultan Agung, sebuah karya sastra Jawa klasik, produk istana banyak menampilkan situasi keagamaan di kerajaan Mataram, saat tumbuh kembangnya kerajaan di masa itu. Istana sebagai pusat pengembangan kebudayaan sangat berperan dalam penyebarluasan agama Islam. Di dalamnya tampil tokoh Sunan Kalijaga, salah satu tokoh wali sanga, tokoh penyebar agama Islam di Pulau Jawa. Kahadiran tokoh tersebut memperkuat pandangan bahwa istana sangat berperan dalam penyebarluasan agama Islam. 
Pengaruh Islam dalam Naskah Babad Nitik Sultan Agung, dijelaskan bahwa rakyat Mataram telah menerima lailatul qodar, demi kesempurnaan negara, disarankan untuk memeluk Islam. Bahwa agama Islam dianggap agama suci yang dipercayakan oleh Tuhan. Mereka memuliakan Nabi Muhamad Saw, sebagai utusan-Nya, Alquran sebagai tuntunan dan Kalimat Sahadat wajib diucapkan dan merupakan syarat untuk memeluk agama Islam, $\quad$ (P. IV.3-6 $)^{13}$.

Sang raja masih menjalankan tapa brata di gunung Girilaya, berserah diri kepada-Nya. Permohonan itu diterima, Tuhan mengabulkan ditandai oleh tanda-tanda alam, laut bagaikan mendidih, gunung Merapi gemuruh, puncaknya bergoncang, keluar kilat, menunjukkan kekuasaan-Nya dan kekuatan sang raja. Berikut kutipannya.

Aneng gunung Girilaya apitekur, sujud sru neges suksma di, kacipta norgan pandulu, bumi langit wus kapusthi, kojar samodra lir umob.

Sru merbawa hardi Merapi, ju mlegur, kang pucak geter kumitir, cumlorot lidah gumawur, mastuti kang brangteng Widi, mring sang sudibya kinaot (P. IV. 8-9) ${ }^{14}$.

Kutipan di atas menunjukkan terjadi sinkritisme antara kepercayaan Jawa dengan ajaran Islam. Sebab di dalam agama Islam tidak terdapat ajaran bertapa di suatu tempat untuk mendapatkan sesuatu yang diinginkan. Dalam pandangan Islam hal itu dianggap musrik karena menyekutukan Tuhan. Akan tetapi dalam budaya Jawa mencapai tujuan yang mulia sebaiknya disertai dengan usaha batin, dan tawakal.

\section{(b) Menjalankan perintah-Nya}

Dalam memeluk agama, umat manusia dihadapkan pada kewajiban dan berbagai larangan-Nya. Kewajiban umat dalam menjalankan perintah agama sesuai dengan tuntunan masingmasing agama. Dalam agama islam kewajiban umat yang harus dilakukan diatur dalam rukun Islam, yang berjumlah 5, yaitu mengucapkan kalimah syahadat, menjalankan salat, membayar zakat, berpuasa pada bulan Ramadan, dan menunaikan ibadah haji.

Dalam Naskah Babad Nitik Sultan Agung, menjalankan perintah agama, tampak pada kewajiban salat Jumat dan puasa. Salat Jumat merupakan salah satu kewajiban seorang muslimin. Suatu saat Sultan menyarankan agar namanya diukirkan di dalam kubah masjid. Ki penghulu menolak. Khawatir musrik. Sebab memasukkan nama sang raja dalam masjid merupakan tindakan yang luar biasa (nganeh-anehi). Sultan bersabda lemah lembut. $\mathrm{Ki}$ pengulu disuruh menanyakannya ke Mekah. Akhirnya Kyai Akhmad Kategan menyetujui. Ki Pengulu diajak Shalat Jumat di Mekah. Tak berapa lama keduanya tiba di 
mekah. Peristiwa itu membuatnya heran dan kagum. Berikut kutipannya. Sang Nata narimeng kalbu, pracaya aturing patih, sang nata arum ngandika, kakangmas tas sun rasani, asmengsun mengko lebokna, ing khubah sajroning masjid, (P. 31. 3) $)^{15}$.

Kutipan di atas menunjukkan bahwa penulisan nama seseorang dalam sebuah masjid bagi umat Islam, terutama para ulama dianggap suatu kemusrikan. Akan tetapi bagi Sultan hal itu diperbolehkan. Mungkin karena tidak ada aturan yang pasti. Walau ki pengulu menyetujuai, tetapi ia tetap meragukannya. Ia khawatir sang raja marah kepadanya. Bait-bait berikutnya menjelaskan bahwa ki pengulu diusir. Tetapi segera disuruh masuk kembali diajak berkelana naik haji tanpa kendaraan. Mereka membawa bekal secukupnya. Setibanya di tengah hutan kantong berisi dinar itu sobek, uangnya tercecer, habis, (P. 31.1619) ${ }^{16}$.
Kutipan di atas menunjukkan bahwa selain menjalankan ibadah salat dan puasa umat Islam juga diwajibkan naik haji bagi yang mampu. Karena uangnya tercecer, mereka menyeberangi laut naik daun bambu dan daun beringin. Atas kemurahan-Nya Tuhan mengabulkan. Mereka tiba di Mekah, menemui Iman Supingi, sembahyang Jumat, dan mendapat air zamzam berkhasiat dapat mengobati berbagai penyakit (P. 31. 23-27) ${ }^{17}$.

Dalam naskah Babad Nitik Sultan Agung, terdapat dua macam sunah, sunah muakad dan sunah ngain. Sunah muakad adalah hukum Islam yang boleh dilakukan bahwa suatu perbuatan bisa dilaksanakan bersama-sama, sedangkan sunah ngain, setiap umat harus menjalankannya. Berikut kutipannya.

Angyetekken nenggih ing pangawasanira, samanten amarengi, wektu siyam sawal, pangulu wus uninga, yen Sang Nata datan apti, sunat muakat, mung sunat ngaen yekti.

Kang kinarsan dening Kanjeng Sri Narendra, awit pamanggih (153) aji, yen sunat muakat, pangulu bae cekap, yen sunat ngain yekti, samya kwajiban, sadaya anglampahi (P. 30.9-10) ${ }^{18}$.

Berpuasa merupakan salah satu kewajiban umat Islam. Hal itu dijelaskan dalam dalam rukun Islam, yang ketiga, menjalankan puasa Ramadan. Selain menjalankan kewajiban, dalam naskah juga terdapat sunah muakad, salah satu di antaranya puasa pada bulan Syawal. Sunah muakad adalah hukum Islam yang mengatur perbuatan manusia, bila suatu pekerjaan dilakukan akan mendapat pahala, sementara bila ditinggalkan 
tidak berdosa. Namun demikian sunah muakad dianggap sebagai sunah setengah wajib. Misalnya berpuasa pada bulan Syawal atau nyawal. Pengulu tahu bahwa sang raja tidak menjalankan. Sang raja disarankan bahwa beliau saharusnya berpuasa sebab dianut oleh rakyat. Sebagai panutan seharusnya ia memberikan teladan yang baik, menjalankan perintah dan menjauhi larangan agama. Teguran itu dijawab dengan kata-kata keras bahwa tidak semua umat menjalankan puasa sunah. (P. 30:18$21)^{19}$.

Kutipan di atas menunjukkan bahwa terdapat perbedaan pendapat tentang ajaran agama antara raja dengan ulama. Keduanya memiliki pendapat berbeda. $\mathrm{Ki}$ penghulu menyarankan bahwa sebagai seorang raja, panutan rakyat seharusnya menjalankan puasa Nyawal. Tetapi Jeng Sultan tidak mau. Kalau demikian ki penghulu khawatir umat manusia akan menganggap remeh dan tidak patuh terhadap ajaran Islam. Beliau berjanji bahwa keesokan harinya ia akan menjalankan puasa Sunat muakad. Ki pengulu diminta untuk menjadi saksi bahwa Sultan memiliki ngelmu wirasat.

Keesokan harinya sang pengulu dan para ketib ( petugas keagamaan), datang lebih pagi. Sultan masih tidur. Setelah bangun, sultan duduk di dhampar. Pengulu dan ketib disuruh maju. Mereka harus menjadi saksi bahwa sang raja berpuasa. Sejak pukul
6 pagi. Menjelang pukul 7.00, Dampar tempat duduk sang raja naik, terbang makin lama makin tinggi mendekati matahari. Melihat keanehan itu permaisuri dan para dayang heran dan bingung. Sang pengulu dan para ketib tertegun, bergeming, tidak bisa berbuat banyak. Sultan mengatakan selamat tinggal dan akan berkumpul bersama umat yang berpuasa seperti dia, (P. 30. $27-29)^{20}$

Kutipan di atas menunjukkan bahwa selain puasa yang dianjurkan oleh agama Islam, orang Jawa juga memiliki cara tersendiri dalam menjalankan puasa. Sebab dalam budaya Jawa, terdapat berbagai macam puasa, untuk mendekatkan diri kepada Yang Maha Esa. Selain itu puasa juga merupakan saarna untuk mencapai suatu tujuan yang mulia. Sebab mereka percaya untuk mencapai suatu tujuan manusia harus berusaha, berdoa dan tawakal.

\section{(2) Hubungan Manusia dengan} Alam

Dalam kehidupan bermasyarakat, manusia berinteraksi dengan sesama dan alam lingkungannya. Oleh sebab itu, masyarakat selalu mencari keseimbangan dengan jalan ramah lingkungan dan berusaha bersahabat dengan lingkungan. Manusia memandang bahwa alam sebagai suatu hal yang dapat dilawan dan harus ditaklukkan. Manusia harus selalu mencari keselarasan dengan alam. ${ }^{21}$ Koentjaraningrat

(1982:439) 
mengatakan manusia banyak danyang, makhluk halus yang dihadapkan berbagai kekuatan alam, menguasai atau menghuni suatu tempat. mereka berusaha menyesuaikan diri, Umumnya mereka berinteraksi walau walaupun demikian tidak merasa takluk kepada alam karena memang tidak mempunyai kekuatan untuk menentang alam. Oleh sebab itu, mereka memilih menyelaraskan diri.

Berkaitan dengan penyelarasan diri dengan alam, masyarakat Jawa menghubungkan dengan animisme dan dinamisme. Dikaitkan dengan keberadaan makhluk halus penjaga alam semesta yang harus dihormati sehingga terjadi hubungan timbal balik saling menghormati, sebagai ciptaan Allah Swt. Karena keberadaannya tidak diketahui oleh umat manusia, maka manusia menyelaraskan diri.

Dalam usaha menyelaraskan diri dengan alam, masyarakat Jawa merealisasikan dengan selamatan. ${ }^{22}$ Koentjaraningrat (1987: 341), menjelaskan bahwa masyarakat Jawa melaksanakan berbagai selamatan yang dikelompokkan menjadi (1) selamatan yang berkaitan dengan siklus hidup manusia, (2) bersih desa, (3) selamatan yang berkaitan dengan hari besar agama, (4) menolak bala atau ngruwat, dan (5) kaul atau nadhar. Pendapat itu juga didukung oleh ${ }^{23}$ Geertz (1983). Masyarakat percaya akan keberadaan makhluk halus menghuni alam lain. Masyarakat mengenal berbagai makhluk halus, seperti memedi, thuyul, lelembut. dsb ${ }^{24}$ Geertz (1983: 19). Di samping itu, mereka juga mengenal interaksi sepihak karena umat manusia tidak bisa berkomunikasi langsung. Salah satu makhluk halus yang dimitoskan adalah Nyai Rara Kidul atau Kanjeng Ratu Kidul. Dalam Babad Nitik dia Retna Suwidi, putri raja Pajajaran, yang menguasai "Segara Kidul". Dalam analisis hubungan manusia dengan alam, mitos disajikan dalam konteks pelestarian alam dan pemanfaatan alam.

\section{(a) Pelestarian Alam}

Naskah Babad Nitik Sultan Agung, sebagai hasil cipta sastra Jawa, juga memuat kearifan lokal, terutama yang berkaitan dengan penyelarasan diri dan pelesterian alam. Dalam teks tersebut penyelarasan diri dengan alam, berkaitan dengan kepercayaan masyarakat tentang adanya makhluk halus penjaga suatu tempat, sing mbaureksa, tampak pada bagian yang menceritakan hubungan antara Sultan agung dengan Nyai Rara Kidul. Dalam Suluk Plencung, Nyai Rara Kidul adalah ratu yang menguasai makhluk halus di sepanjang segara kidul, pantai selatan Pulau Jawa. Dalam naskah itu dijelaskan bahwa Sultan Agung menikah dengannya. Hal itu terjadi atas saran Sunan Kalijaga bahwa mereka memang harus bersatu. Keduanya ditemui oleh Sunan Kalijaga. Berikut kutipannya. 
Raja dewi tiharda trusthaning kalbu, gya manjing caket sang yogi, jeng Sunan Maksih neng pintu, kocap kang ngumbara prapti, jeng Sunan nyapa gupoh. Lah bageya ki Bagus anom Matarum, paran darunaning prapti, teka deliran muwus, durung mangsa kita mriki, baliya sang Bagus anom.

Kang sinung ling nembah matur amidhupuh, patikbra ajrih sang yogi, wonten cobaning hyang agung, ngandika rum Sunan Kali, pyarsakna jebeng jarwengong.

Wus ginaib paningkahmu lan ni ratu, kalinya kang bumi langit, baskara candra puniku, waline ingsun nekseni, aja kita walang atos.

Sang sudibya balinya maksih pitekur, sang prabu dewi udani, bali yitmane sang bagus, dhawuh maring kang para wangi, kinen nempuh mring sang anom, (P. 4. 22-26) ${ }^{25}$.

Kutipan di atas menjelaskan bahwa pernikahan antara Nyai Rara Kidul dengan Sultan Agung terlaksana atas saran Sunan Kalijaga. Nyai Rara Kidul meragukan niat tersebut. Ketika Sultan Agung sedang bertapa di Girilaya, dijumpai oleh Sunan Kalijaga yang mengatakan bahwa pernikahan itu memang takdir. Disaksikan oleh bulan, bintang, matahari, bumi dan langit, Sunan Kalijaga bertindak sebagai wali.

Kedudukan Nyai Rara Kidul, dalam pandangan masyarakat Jawa, adalah ratu penguasa makhluk halus di sepanjang pantai selatan, makhluk yang menghuni alam lain. Manusia harus menyelaraskan diri dengan alam. Dalam hal ini menjaga kelestarian alam, untuk mamayu hayuning bawana, demi kesejahteraan dunia.

Era global mengubah pandangan masyarakat. Alam yang semula dijaga kelestariannya sekarang dirusak. Perusakan alam mengakibatkan berbagai bencana karena alam merasa diremehkan. Alam pun marah, banyak makan korban jiwa. Sebab bencana tidak memilih korban. Namun demikian umat manusia banyak yang kurang menyadari pentingnya pelestarian alam, termasuk menjaga hubungan antara manusia dengan makhluk penghuni alam lain.

Di alam semesta, terdapat makhluk lain yang perlu dipiara kelestariannya, yaitu flora dan fauna. Kedua makhluk itu bisa dimanfaatkan oleh manusia, oleh sebab itu harus dilestarikan. Dalam naskah tampak bahwa ketika Sultan Agung akan membangun makam, ada kendala, dengan hari naas. Ketika sedang membabad hutan terdapat berbagai macam binatang yang sedang beristirahat. Para punggawa yang sedang bekerja melaporkannya kepada sang raja. Akan tetapi sang raja salah paham bahwa yang dilaporkan adalah ular, tetapi dikira akar, maka setelah dibabad semua ular merubah menjadi akar. Sabda pandita ratu, apa yang diucapkan oleh seorang raja bagaikan ucapan sang pendeta, maka apapun ucapan itu terjadi. Hal itu dipercaya oleh masyarakat Jawa bahwa 'oyod' selain berarti akar juga merupakan 
bentuk krama dari ular, (P. 28. 24$25)^{26}$.

Kutipan di atas menunjukkan bahwa untuk membangun sebuah penghunian atau prasarana umum, membutuhkan lahan. Hutan di dekat Girilaya, dibabad untuk pemakaman. Berbagai binatang menyingkir karena terpengaruh oleh sabda sang raja. Dengan demikian pelestarian alam kurang diperhatikan. Namun demikian hal itu bisa disikapi dengan penanaman kembali agar tidak terjadi bencana banjir atau tanah longsor, karena tidak ada akar penahan air.

\section{(b) Pemanfaatan Alam}

Tuhan menyediakan alam untuk kepentingan umat manusia. Makan dan pakaian merupakan kebutuhan hidup. Salah satu pemanfaatan alam untuk memenuhi kebutuhan umat manusia di negara agraris adalah penyiapan lahan pertanian. Padi sebagai makanan pokok masyarakat Indonesia. Pulau Jawa yang subur, dikenal dengan semboyan gemah ripah loh jinawi, subur kang sarwa timndur, murah kang tinumbas, sebagai lumbung padi. Kesuburan pulau Jawa juga dituangkan dalam beberapa karya sastra. Salah satu karya yang menunjukkan betapa pentingnya padi dalam kehidupan masyarakat Jawa adalah Naskah Babad Nitik Sultan Agung.

Dalam Naskah Babad Nitik Sultan Agung, dijelaskan bahwa membawa bibit padi dari negara Campa, disarankan agar ditanam agar menjadi mata pencaharian. Hal itu menjadi sebab orang Jawa makan nasi. Mereka merasa tenteram setelah makan nasi dan mereka giat dalam bertani terutama menaman padi. Berikut kutipannya.

Dene kang wit wiji pari, Jeng Sultan Agung kang manra, welingira Sunan L (171) pen, yeku wiji sangking cempa, kinen sami nanema, karsanira Jeng Sultan Agung, dadiya pangupajiwa.

Katelah ngantya semangkin, wong Jawa karemira, amangan sega karmane, limut maring kasutapan, ayem abukti sega, sengkut genira nenandur, widagda nir pratama, $(\mathrm{P} .35 .15-17)^{27}$.

Kutipan di atas menunjukkan bahwa masyarakat Jawa makanan pokok masyarakat Jawa atau rakyat Mataram adalah nasi. Bertani menjadi pekerjaan utama masyarakat, bahkan Dewi Sri dimitoskan sebagai dewi kesuburan, dewi padi atau dewi among tani yang Mereka menonton. Berikutkutipannya. dipuja oleh masyarakat. Namun demikian dalam naskah tersebut dijelaskan bahwa padi yang menjadi makanan pokok masyrakat itu berasal dari negara asing, yaitu dadi campa. Oleh-oleh Sultan Agung ketika berkelana, rakyat kagum melihat padi. 
Dupi prapta wiji pari, utusan dalem Cempa, sreg gumuruh keh wong nonton, sangking indahe kang warna, pinacong penggawanya, rembyak-rembyak teka bagus, dadya misuwur kang mulat.

Wus katur mring Sribupati, Kanjeng Sultan rum ngandika, Sepetmadu apa kae, kang dadi getering jaba, wonten si ki parekan, cumlathok (172) mring lurahipun, Ki Lurah utusan nata.

Sangking Cepa sampun prapti, wiji pari kang binekta, kamantyan endah warnane, manira wingi neningal, wonten ing kepatihan, nganyela wonten ing ngayun, ore-oreyan apelak (P.30.19-21) ${ }^{28}$.

Kutipan tersebut menunjukkan bahwa bibit padi itu berasal dari Campa. Kedatangan bibit itu membuat decak kagum masyarakat. Begitu indah, berkilau, dan mengurai. Padi itu menjadi tanaman kalangenan (kegemaran) dan hiburan sang raja. Beliau menyuruh para punggawa agar segera menyemaikan padi itu, dan membuat lahan dengan jalan membabad hutan, serta menyediakan lumbung. Sang raja akan menanam padi itu, dan permaisuri akan menanam pari wangen, yang baunya harum. Tempat menanam padi itu dibatasi dengan penanaman kelapa gading, sebanyak seribu batang ditanamnya, dipersiapkan untuk membuat minyak, untuk memasak dan merupakan penghasilan tambahan. Karena selain menghasilkan minyak kelapa ujungnya digunakan untuk bumbu dan memasak berbagai macam makanan, (P. 30 $)^{29}$.

Kutipan di atas menunjukkan bahwa selain menanam padi, rakyat Mataram juga disarankan menanam kelapa di pekarangan rumah dengan harapan bisa menghasilkan minyak, sebagai penghasilan tambahan. Selain itu dari kutipan di atas tampak bahwa pemanfaatan alam dalam naskah Babad
Nitik Sultan Agung, direalisasikan dengan penanaman padi, sebagai bahan makanan pokok masyarakat, juga penanaman kelapa agar menjadi bahan baku minyak goreng. Kedua hal tersebut hingga kini masih tampak bahwa makanan pokok masyarakat Mataram adalah beras dan di Jawa kalapa dijadikan bahan baku minyak goreng.

\section{(3) Hubungan antara Manusia dengan Masyarakat}

Sebagai anggota masyarakat, manusia berkomunikasi di antara para anggotanya. Mereka terikat dan tunduk pada tata aturan dan adat kebiasaan di dalamnya. Mereka menginginkan kedamaian, ketenteraman, dan keharmonisan. Peran individu dalam masyarakat kurang begitu tampak. Mereka lebih menunjukkan kebersamaan dan bergotong royong. Dalam menghadapai berbagai masalah dipecahkan bersama, berpedoman pada konsep saiyeg saekakapti. Konsep tersebut menimbulkan rasa melu handarbeni (rasa memiliki). Dengan demikian mereka tidak merasa canggung dalam menghadapi masalah secara bersama-sama. 
Umat manusia selain membina hubungan antara manusia dengan Tuhan, mereka juga berinteraksi secara horisontal, dalam arti membina hubungan antarmanusia. Karena saling bergantung, manusia membina kerja sama dalam masyarakat yang berdasar pada konsep kerja sama. Di masyarakat tertuang nilai-nilai yang dianggap baik dalam kehidupan bersama. Nilainilai yang dianggap baik itu dipertahankan dan dilestarikan dimanfaatkan sebagai panutan.

Nilai budaya dalam hubungan manusia dengan masyarakat adalah nilai-nilai yang berhubungan dengan kepentingan anggota. Anggota masyarakat sebagai individu berusaha mematuhi aturan demi kepentingan bersama. Setiap anggota beranggapan kepentingan bersama lebih penting daripada kepentingan pribadi. Mereka berusaha meminimalisasikan persaingan dan pertentangan. Nilai budaya yang cukup dominan dalam hubungan antara manusia dengan masyarakat adalah gotong royong, musyawarah, patuh pada adat dan keadilan (Jamaris, 1993:6) ${ }^{30}$.

Dalam Babad Nitik Sultan Agung, nilai budaya dalam hubungan manusia dengan masyarakat dibatasi pada musyawarah dan kerukunan antarwarga. (a) Musyawarah untuk Mufakat

Manusia diciptakan Tuhan sebagai makhluk pribadi sekaligus makhluk sosial. Manusia bisa memiliki arti dalam kaitannya dengan manusia lain dalam masyarakat. Seseorang tidak dapat berbuat sesuatu, tanpa bantuan dan kerja sama dengan orang lain. Kekuatan manusia sebetulnya terletak pada kemampuan bekerja sama. Dalam kehidupan bermasyarakat dituntut bagaimana manusia memberikan arti dan memandang hubungan antara manusia dengan masyarakat. Sebagai anggota masyarakat ia memerlukan orang lain.

Untuk mencapai suatu tujuan yang baik manusia tidak bisa mencapainya tanpa bantuan orang lain. Musyawarah untuk mufakat tampaknya bisa memberikan solusi terbaik. Pendapat orang lain bisa dipakai sebagai bahan pertimbangan dalam mengambil keputusan. Dalam naskah Babad Nitik Sultan Agung, pengarang juga menuangkan pandangan tentang kerja sama dan musyawarah dalam karyanya. Salah satu wujud musyawarah itu tampak pada saat pernikahan Sultan Agung dengan Retna Suwidi (nama lain Nyai Rara Kidul). Sunan Kalijaga mengadakan pendekatan kepada keduanya untuk musyawarah. Saat itu Sultan Agung sedang bertapa di Girilaya. Berikut kutipannya. 
Duk semanten Sunan Kali jageng pintu, gya umarek raja dewi, nembah matur asidhupuh, dahat begjamba kapanggih, sang maha muni nebda alon.

Ana karya ni rara ing laksitamu, umatur sang prabu dewi, niskareng sadaya katur, niyup Kanjeng Sunan Kali, lan nabda ywa wangkot,

Nataningdyah malat ati aturipun, mugi ta panuwun mami, lamun jakaning Matarum, kapi dreng tuwan belani, manggut ati warata hor.

Raja dewi tiharda trusthaning kalbu, gya manjing caket sang yogi, jeng Sunan maksih neng pintu, kocap kang ngumbara prapti, jeng Sunan nyapa gupoh. (P. $4.19-22)^{31}$.

Kutipan di atas menunjukkan bahwa Sunan Kalijaga berada di pintu surga, Nyai Rara Kidul menemuinya minta saran tentang pernikahannya dengan Sultan sebab Sultan masih meragukannya. Dalam hal ini Sunan Kalijaga menjadi telangkai.

\section{(b) Kerukunan}

Crah agawe bubrah rukun agawe santosa. Sebuah ungkapan yang mengarah kepada kerukunan antarumat manusia. Hal ini juga berkaitan dengan persatuan dan kesatuan bangsa. Bila masyarakat membina kerukunan antarumat, ketenteraman dan kedamaian akan terwujud. Dalam Naskah Babad Nitik Sultan Agung, kerukunan masyarakat tampak pada saat Sultan mendapat wangsit dari Sunan Kalijaga, untuk mengumpulkan binatang buruan. Pangeran Purbaya, dipercaya untuk menugawi punggawa yang akan dipekerjakan (P. 2.22-24) ${ }^{32}$. Warga masyarakat sangat loyal kepada sang raja. Apa pun yang diperintahkan dikerjakan. Termasuk berburu di hutan Gungng Kidul, mencari berbagai macam binatang buruan, sambil mencari putra raja yang saat itu sedang bertapa. Karena tafakur beliau tidak bisa dilihat dengan mata telangang, tetapi dengan mata hati. Walaupun sebenarnya beliau berada di lokasi itu, diibaratkan tertutup selembar daun, tetapi tak nampak.

\section{(4) Hubungan Manusia dengan}

\section{Sesama}

Manusia adalah makhluk sosial. Mereka hidup berkelompok dan saling membutuhkan. Manusia berkomunikasi dalam pergaulan. Dalam pergaulan sering timbul berbagai masalah, seperti perbedaan pendapat, salah paham, dll. yang sering menimbulkan konflik. Untuk menghindari terjadinya konflik tiap-tiap individu dituntut saling menjaga perasaan orang lain demi ketenteraman dan keharmonisan dalam kehidupan bermasyarakat. Dengan kata lain hubungan antara manusia dengan sesama lebih mengutamakan keselarasan dan keseimbangan, walau dalam masyarakat terjadi konflik yang sulit dihindari. Hal ini merupakan realisasi nilai budaya dalam hubungan antara manusia dengan sesama dalam masyarakat. 


\section{(a) Hubungan kekeluargaan}

Pada awal cerita dijelaskan silsilah kerajaan Mataram, diawali dari Pangeran Mangkubumi, memiliki dua orang putra. Salah seorang diasuh oleh sang raja diangkat menjadi adipati di Sukawati. Sedangkan adiknya Raden Mas Pethak diangkat menjadi adipati di Madiyun. Pangeran Singasari menjadi adipati di Panaraga, (P.17$11)^{33}$. Di keraton Mataram terdapat sisilah raja-raja yang semua mendapat jabatan, di berbagai kraton di bawah naungan Mataram, seperi di Madiyun, Sukawati (Sragen), Panaraga, dll. Pembagian kekerjaan dan jabatan dalam istana Mataram, menunjukkan bahwa di antara keturunan raja-raja tersebut memiliki hak untuk menjadi raja. Oleh karena hanya ada kerajaan mataram, maka pemerintahan di berbagai daerah diperintah oleh para adipati di bawah naungan kerajaan Mataram.

\section{(b) Pernikahan}

Pernikahan merupakan lembaga terkecil unuk membangun rumah tangga. Di Indonesia pernikahan dilaksanakan di bawah Departemen Agama. Dalam naskah Babad Nitik Sultan Agung terdapat penjelasan tentang pernikahan. Misalnya, putra bungsu Pangeran Mandaraka, menikah dengan Adipati Batang, Penembahan senapati memiliki 2 orang permaisuri, putri dari kraton Pajang, putra Pangeran Benawa, yang kedua Ratu
Lung Ayu, berasal dari Panaraga (P.1.7-11) $)^{34}$.

Selain pernikahan antarkeluarga di kerajaan Mataram juga terdapat pernikahanh antara Sultan Agung dengan Nyai Rara Kidul, yang diprakarsai oleh Sunan Kalijaga (P.4.24-25) ${ }^{35}$. Bahwa dalam msyarakat Jawa terdapat pernikahan antara manusia dengan makhluk halus, yaitu antara Sultan agung dengan Nyai Rara Kidul, yang hingga kini masih dipercaya oleh masyarakat Jawa. Kepercayaan terkait dengan dongengdongeng yang terdapat dalam naskahnaskah yang ditulis para pujangga keraton.

\section{(5) Hubungan Manusia dengan Dirinya}

Selain sebagai makhluk sosial, manusia juga sebagai pribadi yang membutuhkan ketenangan hidup secara lahiriah maupun batiniah. Keinginan hidup tersebut antara lain, keberhasilan dalam mencapai cita-cita, kebahagiaan, ketenteraman, kedamaian yang ditentukan oleh kepribadian dan kearifannya dalam menjaga keseimbangan dunia, dan keselarasan hubungan antarsesama manusia. Hal ini bisa terwujud bila masing-masing pribadi menyadari perannya dalam masyarakat, sebagai pribadi dan sebagai anggota masyarakat. Sebagai pribadi manusia memiliki berbagai peran dan watak. Watak tersebut yang menentukan 
hubungan antara manusia dengan dirinya.

Dalam Naskah Babad Nitik

Sultan Agung, hubungan manusia dengan dirinya terdapat pada bagian yang menceritakan kesedihan ki pengulu setelah ia menolak Jeng Sultan untuk mencantumkan namanya di kubah Masjid Mekah. Pada awalnya menolak dengan alasan takut sang raja musrik dan terasa aneh. Ia merasa tidak enak. Ki pengulu tidak percaya. Akan tetapi setelah diajak shalat Jumat di Mekah akhirnya ia menyetujui. Berikut kutipannya.

Sang Nata narimeng kalbu, pracaya aturing patih, sang nata arum ngandika, kakangmas ta sun rasani, asmengsun mengko lebokna, ing khutbah sajroning masjid.

Pengulu mambengi kalbu, sumelang rukune salin, wewah ing pundit gonira, kawula anuwun ajrih, sapengkeripun jeng duta, kang kasebut jroning tulis.

Boten kalong wuwuh, panduka kinen mewahi, nglebetaken asma narendra, kalebet nganeh-anehi, saklangkung jrih kawula, dereng sakeca ingati.

Sang Nata ngandika arum, sira tan pracaya mami, takona dhewe mring Mekah, nanging yen kepara yekti, aywa sira takon dosa, Pengulu anyandikani. (P. XXXI. $3-6)^{36}$.

Kutipan di atas menunjukkan bahwa Ki Pengulu merasa sedih, merasa bersalah, terharu, menyesal karena pasti akan dimarahi. Bait berikutnya menceritakan kekhawatiran ki pengulu. Ia gundah. Penyesalan dan kesedihan sering melanda hati seseorang, bila ia berbeda pendapat dengan orang lain. Ia pun khawatir akan mendapatkan marah dari sang raja. Apa lagi saat itu sang raja berada di rumah ki pengulu yang sangat miskin. Ia sudah tidak memiliki.
Ia juga khawatir diusir dari tempat tingalnya.

Selain itu pengaruh tapa sang raja diterima oleh Hyang Kuasa, mendapatkan anugerah agar menyebarkan agama Islam di wilayah kerajaannya. Hal itu menyebabkan Nyai Rara Kidul bersedih karena terjadi huru-hara, laut bagaikan diguncang, Ia berkata dalam hati. Berikut kutipannya

Sangking dahat mesu sang narpa suhunu, dadya nekakken gora gring, janawi kadya kinebur, yata sang aprabu dewi, manguneng tyasmung wirangrong.

Angandika nataningdyah jroning kalbu, paran daruane iki, de isining prajaning-sun, padha kataman wiyadi, nging raja dewi wus anon.

Yen kang karya ruharsane gung, sang narpa siwi Matawis, samangke kang wus pikantuk, kamulyan kinen amerdi, agama suci gunging wong (P. 4. 12-14) ${ }^{37}$.

Kutipan di atas menunjukkan bahwa sebagai raja, Sultan Agung berusaha mendekatkan diri dengan Tuhan, dengan jalan bertapa. Dengan bertapa 
permohonannya diterima, ia mendapatkan anugerah, dipercaya untuk menyebarkan agama Islam. Di pihak lain, kekuatan tapa sang raja mempengaruhi alam lain, yaitu di kerajaan. Di pantai selatan, terjadi huru-hara. Laut bagaikan dikebur. Hal ini merupakan pertanda bahwa tapanya sang raja diterima oleh Tuhan Yang Maha Kuasa. Dalam masyarakat Jawa kepercayaan seperti ini masih ada.

\section{Simpulan}

Berdasarkan hasil pembahasan di atas, berikut disajikan beberapa butir simpulan, antara lain:

Naskah Babad Nitik Sultan Agung merupakan produk budaya Jawa yang ditulis oleh Pujangga Kasultanan Ngayojakarta Hadingrat pada abad ke19. Naskah tersebut menjadi koleksi Museum Sonobudoya Yogyakarta, dengan kode rnomor SB. No. 30.

Dalam Babad Nitik Sultan Agung, nilai budaya hubungan manusia dengan Tuhan mengarah kepada ajaran Islam. Oleh sebab itu, analisis nilai budaya dalam hubungan manusia dengan Tuhan diarahkan pada kepercayaan masyarakat yang berkaitan dengan agama Islam.

Berkaitan dengan penyelarasan diri dengan alam, masyarakat Jawa menghubungkan dengan animisme dan dinamisme. Dikaitkan dengan keberadaan makhluk halus penjaga alamsemesta, sehingga terjadi hubungan timbal balik saling menghormati, sebagai ciptaan Allah Swt. Oleh karena keberadaannya tidak diketahui oleh umat manusia, maka manusia yang harus menyelaraskan diri dengannya.

Nilai budaya dalam hubungan manusia dengan masyarakat adalah nilai-nilai yang berhubungan dengan kepentingan anggota. Sebagai individu, mereka berusaha mematuhi aturan demi kepentingan bersama. Kepentingan bersama lebih penting daripada kepentingan pribadi. Mereka berusaha meminimalisasikan persaingan dan pertentangan. Nilai budaya yang cukup dominan, gotong royong, musyawarah, patuh pada adat, dan keadilan. Dalam Babad Nitik Sultan Agung, nilai budaya tersebut dibatasi pada musyawarah dan kerukunan antarwarga.

Manusia adalah makhluk sosial. Mereka hidup berkelompok dan saling membutuhkan. Manusia berkomunikasi dalam pergaulan. Dalam pergaulan sering timbul berbagai masalah, seperti perbedaan pendapat, salah paham, dll. yang sering menimbulkan konflik. Untuk menghindari konflik tiap-tiap individu dituntut saling menjaga perasaan orang lain demi ketenteraman dan keharmonisan dalam kehidupan bermasyarakat. Dengan kata lain hubungan antarsesama lebih mengutamakan keselarasan dan keseimbangan. Dalam naskah Babad Nitik Sultan Agung, nilai budaya ini tampak pada hubungan kekeluargaan, saling membantu dan pernikahan.

Dalam Naskah Babad Nitik Sultan Agung, hubungan manusia dengan dirinya terdapat pada bagian 
yang menceritakan kesedihan ki pengulu setelah ia menolak Jeng Sultan untuk mencantumkan namanya di kubah Masjid Mekah. Dengan alasan takut sang raja musrik dan terasa aneh.
Ia merasa tidak enak. Ki pengulu tidak percaya. Tetapi setelah diajak salat Jumat di Mekah akhirnya ia mau mematuhi.

\section{DAFTAR PUSTAKA}

${ }^{1}$ Robson, R.O. 1978. Pengkajian Sastra-Sastra Tradisional Indonesia. Bahasa dan Sastra, Tahun IV Nomor 6 Tahun 1978.

${ }^{2}$ Ratna, Nyoman Kutha, 2002. Paradogma Sosiologi Sastra. Yogyakarta: Pustaka Pelajar.

${ }^{3}$ Robson. S.O. 1994. Prinsip-Prinsip Filologi Indonesia. Jakarta: Pusat Pembinaan dan Pengembangan Bahasa.

${ }^{4}$ Purnomo, Bambang. 2007. Filologi dan Studi Sastra Lama. Surabaya: Bintang Surabaya.

${ }^{5}$ Robson, R.O. 1978. Pengkajian Sastra-Sastra Tradisional Indonesia. Bahasa dan Sastra, Tahun IV Nomor 6 Tahun 1978.

${ }^{6}$ Yunus, Umar. 1986. Sosiologi Sastra. Kuala Lumpur: Dewan Bahasa Malaysia

${ }^{7}$ Ikram, Akhadiyati. 1997. Filologia Nusantara. Jakarta : Pustaka Jaya.

${ }^{8}$ Koentaraningrat. 1982. Kebudayaan Mentalitas dan Pembangunan. Jakarta: Gramedia.

${ }^{9}$ Djamaris, Edward. 1981. "Mengenal Sastra Melayu Klasik, Warisan Sastra Yang Sering Terlupakan” Analisis Kebudayaan I. Jakarta: Depdikbud.

${ }^{10}$ Pigeaud. 1967.Literature of Java, Katalogus-Reisone of Javaansche Manuscrift and Suplement. The Hague Martinus Nijhoff.

${ }^{11}$ Zoetmulder, PJ. 1983. Kalangwan: Sastra Jawa Kuna Selayang Pandang. Jakarta: Djambatan.

${ }^{12}$ Koentjaraningrat. 1984. Kebudayaan Jawa. Jakarta: Balai Pustaka.

${ }^{13}$ Naskah Babad Nitik Sultan Agung

${ }^{14}$ Naskah Babad Nitik Sultan Agung 
${ }^{15}$ Naskah Babad Nitik Sultan Agung

${ }^{16}$ Naskah Babad Nitik Sultan Agung

${ }^{17}$ Naskah Babad Nitik Sultan Agung

${ }^{18}$ Naskah Babad Nitik Sultan Agung

${ }^{19}$ Naskah Babad Nitik Sultan Agung

${ }^{20}$ Naskah Babad Nitik Sultan Agung

${ }^{21}$ Koentaraningrat. 1982. Kebudayaan Mentalitas dan Pembangunan. Jakarta: Gramedia.

${ }^{22}$ Koentjaraningrat. 1987. Sejarah Teori Antropologi I. Jakarta: UI Press.

${ }^{23}$ Geertz (1983)

${ }^{24}$ Geertz (1983)

${ }^{25}$ Naskah Babad Nitik Sultan Agung

${ }^{26}$ Naskah Babad Nitik Sultan Agung

${ }^{27}$ Naskah Babad Nitik Sultan Agung

${ }^{28}$ Naskah Babad Nitik Sultan Agung

${ }^{29}$ Naskah Babad Nitik Sultan Agung

${ }^{30}$ Jamaris (1993)

${ }^{31}$ Naskah Babad Nitik Sultan Agung

${ }^{32}$ Naskah Babad Nitik Sultan Agung

${ }^{33}$ Naskah Babad Nitik Sultan Agung

${ }^{34}$ Naskah Babad Nitik Sultan Agung

${ }^{35}$ Naskah Babad Nitik Sultan Agung

${ }^{36}$ Naskah Babad Nitik Sultan Agung

${ }^{37}$ Naskah Babad Nitik Sultan Agung 